\title{
ICT: Impacting Teaching and Learning
}

\author{
Sajad Mohammad Khan \\ Scientist, PG Department of \\ Computer Sciences, University \\ of Kashmir, J\&K, India
}

\author{
Muheet Ahmed Butt, \\ Scientist, PG Department of \\ Computer Sciences, University \\ of Kashmir, J\&K, India
}

\author{
Majid Zaman \\ Scientist, Directorate of IT and \\ SS, University of Kashmir, J\&K, \\ India
}

\begin{abstract}
The high growth in education is increasing the demand for flexible and innovative approaches to Teaching - learning in which information technology can play a crucial role. In an educational system "teaching" and "learning" are the two major activities besides "assessment" which is a coordinating activity. The Information Communication Technology (ICT) has a potential to transform the different areas of the educational system. In this paper our focus is on identifying the challenges prevailing in our educational system and proposing the role of Information Communication Technology practices in its successful implementation. This paper also provides some recommendations which could be used as a catalyst for promotion of information communication technology services in both teaching and learning.
\end{abstract}

Keywords: Information, Communication, Teaching, Learning and Assessment.

\section{INTRODUCTION}

In recent times, this new world has observed a fast increase in many technological novelties. This age of Information Communication Technology has steered in the arrival of the electronic computer system among other modern tools. At present the Information Communication Technology has really infused nearly all aspects of human lives. Computers have these days encompassed almost all facets of human endeavors. So much has been written on it and its relatedness to all areas of human disciplines, which include computer/information technology, engineering, agriculture etc.

As Information Technology is not a remedy for all of the deficits associated with our educational system, it offers the potential not only for significantly enhancing learning capabilities for all learners, but also for transforming the way we want to learn [4]. In an educational system ultimately two fundamental activities are carried out in the form of teaching and learning. These activities involve huge resources of both state as well as public with the ultimate objective of effective deliverance. The role of the assessment system in this type of the environment is to co-ordinate the teaching learning activities and evaluates the system performance.

Therefore broadly speaking the following are the activities in an educational system as Teaching, Learning, Assessment and other services. The conventional system of education particularly its assessment system is extremely stressed and has virtually limited its functioning to the conduct of examinations and declaration of results. This has significantly affected the performance of the entire system. Presently it is found that the role of ICT in the educational sector is mostly limited to deliverance of services besides few more activities whereas the challenges are manifold although the advances in information and communication technologies have the potential to enhance lifelong learning [3]. These technologies can be used to address the changing demands within the educational sector for more flexible learning, for extension of educational services to national and international markets; and for more cost-effective delivery of education and related services in an increasingly competitive environment.

\section{CHALLENGES AHEAD}

The four different areas of activities identified above are in state of extreme dynamics and the conventional system is unable to cope up the challenges associated with new opportunities and developments. Some of the main challenges in each of the activities of an educational system are as follows:

○ Teaching Challenges: The Challenges with the teaching include:

- Planning lectures so that teacher - learner participation gets maximized.

- Efficient transformation and dissemination of vital information

- To encourage the student community with the concept of "learn by doing."

- Making the most of the talents of the students, irrespective of their physical and mental disabilities.

- Learning Challenges: The learning scenario is also in state of extreme dynamics and some of the main challenges associated with it are as under:

- Providing information and knowledge anywhere, anytime, anyway and anyhow.

- Allow more flexible access to education reducing barriers of time and place of study.

- Acquire new skills in a way that is compelling and engaging.

- Participate in networked and face-to-face communities of learners composed of teachers, mentors, domain experts, and "cognitive" tutors that collectively approach the effectiveness of a one-onone human tutor.

- Using simulation for problem solving approaches.

- Barrier of languages is made irrelevant

- Assessment Challenges: The deliverance of any education system is largely dependent on its system of examination (assessment). The development of an 
assessment system which meets its prime objectives of achieving desired validity and reliability is a real challenge at global level. Some of the challenges in an assessment system are:

- Continuous Assessment Process

- Design the Assessment System in such a way to achieve the desired Validity, Reliability and Transparency.

- Receive continuous and meaningful feedback of assessment.

- Make it comprehensive enough to explore the potential of the candidates.

- Make it healthy enough to develop higher order skills of comprehension in students.

- Make it a student friendly exercise for every topic covered.

- Develop it as an integral part of the education system to co-ordinate the teaching $\&$ learning process.

- Design it in such a way which forces comprehensive reading.

- Challenges in Other Services: The deliverance of services has been an essential element of an educational system. In order to make the system efficient in all spheres the services have to be provided to all its users. Following are some of the main challenges in services:

- Tap into rich, universally accessible digital libraries with books, articles, material, and data sets.

- Dynamic administration and its record and exchange information

- Develop information systems which support all the users of the system for their necessities.

- Provide services which ensure delivery of information anytime and anywhere at affordable costs.

\section{SCOPE FOR ICT}

The advancement in the computer programming has reached a level wherein backed up by the massive databases artificial intelligence is incorporated in the systems. The Research Challenge is to provide learning environments that approach the characteristics as listed above [4]. Such systems, properly used, can produce a significantly better-educated populace by combining advances in learning sciences for human resource development with advances in information technology. The task of developing the desired system involves a number of technical challenges in the following distinct, but interrelated, areas:

\subsection{Cognitive Based Tutors}

The development of a perfect human tutor involves significant resources in terms of both time as well as wealth. The development of a machine based tutor with the present level of computer programming has become a reality - the scope for. It has been observed that it is possible for an automated tutor to improve student performance by roughly one standard deviation from the mean for some high school mathematics students. This is a dramatic result. One reason that such tutors are not widely available is because significant human effort is required to develop the specialized knowledge base for each different subject. In addition, we do not understand fully the conditions under which such a tutor will be effective. Significant progress must be made in crafting knowledge representations that are both interoperable and reusable. We need to develop models of the various styles in which a student learns, as well as appropriate pedagogies and assessment techniques.

Mathtutor is a free website designed to help 6th, 7th and 8th grade students learn math by doing. Carnegie Mellon University researchers Bruce McLaren, Dave Yaron, and Kenneth Koedinger utilized CTAT Flash tutors to investigate whether learning could be improved by personalized, informal language and worked examples in intelligent tutoring, Politeness Tutor, CycleTalk, Researchers created a series of example-tracing tutors that help students design and optimize thermodynamic cycles, such as the Rankine cycle used in power plants.

The knowledge representations that underline such tutors should also be designed to incorporate new knowledge about a subject area, as well as advances in knowledge and techniques associated with both pedagogy and assessment.

\subsection{Simulation-based teaching}

Multimedia has assumed great significance in teaching and learning. It has a tremendous scope for both teaching as well learning even in the most complex systems. An important genre for next-generation educational software, particularly for training scientists, mathematicians, engineers, and technologists, is what might be called a clip model. By loose analogy to the well known galleries of copy-and-paste 2-D clip art, a clip model is an interactive micro-world, typically simulation- or rule-based, that expresses both geometry and behavior of the modeled entity or concept. It is a self-contained object ready to be embedded in a context such as a hypermedia learning module. First, they are designed to be combined to form larger models, for example, a heart model may be connected to a vascular system model and to a lung model to create a composite model that simulates respiration and oxygenation of the blood as it is distributed throughout the body. Second, no single model suffices for all learning purposes. Perhaps dozens, if not hundreds, of heart models are needed to meet the needs of learners at different levels of understanding and with different kinds of backgrounds and learning styles.

Simulation is used in many contexts, such as simulation of technology for performance optimization, safety engineering, testing, training, education, and video games. Training simulators include flight simulators for training aircraft pilots to provide them with a lifelike experience.

\subsection{Online Assessment System}

It has been observed that almost all the areas of the assessment system require major reforms to make it as an effective part of the educational system. The Information Communication Technology has a tremendous scope for use in many operations in an Examination System besides the compilation of results and other student based services. In fact most of the organizations have already switched over to computerized system of compilation of results and even Management Information system supporting the Management in running the system efficiently are already available. Similarly students related information system providing relevant information to the students also exists in Organizations but these support systems do not strengthen the basic design issues and the objectives of the assessment system. In our opinion support 
solutions are required to be developed for all key entities (teachers, students, examination body) involved in the system. Similarly activities like question paper setting, evaluation, conduct of exam etc require to be supported by the technology to ensure development of quality assessment system.

One of the essential components of the teaching learning process is encouraging and creating the system of self studies among the students. In this context teachers have been traditionally giving assignments to the students and it serves the purpose only once each student is given a different assignment and assessed once it is submitted. With the increase in the number of students, assigning different assignments to students and then evaluating each of them is an issue. This unit of the system requires to be modernized by the support of the technology. In this regard we propose that the development of an E-assignment system which shall assign different assignment to each of the student and assess them automatically for their assignment on some other scheduled day without adding any additional burden to the teacher.

\subsection{Just in Time Learning}

It is critical that each individual learner be able to learn in the physical, social, cultural, and virtual context most appropriate to that learner. [1] In addition, the learner may have a much focused objective for a particular learning session. Just-in-time learning over such a broad range of contexts presents a number of technical challenges, including the support of reliable and ubiquitous computing, access and control of remote instruments, flexible digital object sharing, and user interfaces for small-format mobile devices. The automated teacher must tailor delivered information to fit that context and the goals of the just-in- time learner.

\section{RECOMMENDATIONS OF ICT PRACTICES FOR TEACHING AND LEARNING}

The various recommendations [1] for which have been proposed for using ICT practices in a workshop conducted by University of Kashmir, India by the Post Graduate Department of Education are given below:

$>$ Reliable Internet Connectivity is needed to facilitate the students with ICT benefit and ensure its upkeep.

$>$ Accessibility to the ICT facilities by providing hardware/ software in the form of laptops, desktop, PDA's and other allied devices.

$>$ Virtual/ Smart Class rooms need to be established in all Higher Educational Institutions.

$>$ Availably of Competent Human Capital with relevant skill sets.

$>$ ICT must be integrated with curriculum to make it competitive and bring it in tune with contemporary requirements.

$>$ Allocation of funds by the Government for developing infrastructure and required human resources in various fields of ICT.

$>$ People with special needs must have access to ICT facilities as per their special needs.

$>$ ICT would lead to e-learning which would result in having anytime and anywhere access to learning to make it student driven.
$>$ Capacity building measures should be formulated on need based system for various stake holders to sharpen the existing skills and competencies of existing manpower to perform their job descriptions effectively and efficiently.

$>$ Periodic general awareness, training and developmental programs be conducted for various levels of employees at Government as well as private sector irrespective of their size/nature of ownership and control.

$>$ The services of the subject experts with proven track records must be utilized in preparing e-content that will be available to the masses.

$>$ State of the art repositories must be in place in institutions of Higher Learning so that content is available on demand.

$>$ Refresher/ Orientation courses must be regularly conducted for all the stake holders who are involved in imparting training and knowledge in the area of ICT.

$>$ Possibilities of having public/private partnership must be explored for achieving the objectives of ICT.

These suggestions play a very important role in determining various aspects of education using Information Communication Technology practices. These recommendations identify computer as a teacher, tester, tool, data source and a communication facilitator which has a very important role to play in education.

\section{CONCLUSION}

The education plays a key role within society in the process of social change and therefore the target in the societies has changed to a mass system of education. Our vision of teachers and learners immersed in a network of rich learning objects that are continually enriched and enhanced by the participants is achievable through anticipated advances in information technology and learning sciences. As a result of these efforts, we will be closer to achieving such goals as having transformed the country into a knowledge society. These new benefits will be facilitated by geometric advances in semiconductor and magnetic storage, as well as in electronic and optical communications. The international education and training market is a highly competitive industry. Education providers are increasingly investing in innovative and sophisticated marketing. The use of communications and information technologies in education development and delivery is vital if our educational institutions are to achieve competitive success in the international market for higher and professional education.

\section{REFERENCES}

[1] Battacharya \& Saxena, "Information Security" World Comp 2007, June 25-28, 2007, Las Vegas, Nevada, USA, ISBN1-60132-046-9.

[2] MEHARI, Information risk analysis and management methodology, V3, Concepts and Mechanisms, CLUSIF, October 2004.

[3] Alexander, S. Teaching and Learning on the World Wide Web, Paper presented at AusWeb95, the first Australian World Wide Web Conference.

[4] Mehraj ud Din Dar, Muheet Ahmed Butt, Majid Zaman Baba, "Challenges in Educational System: Scope for E- 
Support", J \& K Science Congress University of Kashmir. 25-27 July, 2006

[5] Austin, P. \& Vaughan, C. 1997, Edith Cowan University Web Enrolment System ECUWES, Paper presented at AusWeb97, the Third Australian World Wide Web Conference, 5-9 July 1997.
[6] William Aspray, Mary J. Irwin "Grand Research Challenges", June 2002, Airlie House in Virginia. 